\title{
Tinjauan Budaya atas Kultur Tasawur Berbasis Mursyid Perempuan
}

\author{
Mustofa \\ Universitas / slam Negeri Syarif Hidayatullah Jakarta \\ Jalan Ir. H. Juanda 95 Ciputat 15412. Telp. (021) 7401925. Fax (021) 7402982
}

\begin{abstract}
Male and female, basically, have the same chance as idol muttaqin person, as well as a leader in the earth, including becoming a teacher of tarekat (mursyid). Assigning female as mursyid will not reduce or break the identity of the Sufism group, on the other hand, it is a kind of glorifying and respecting to the God. However, in tasaw uf culture, nost of the rituals conducted by the followers often reflecting the God in the male form. This conception, then, influences the way they lead the group. The common way of practicing the leadership model finally drives into legalizing the male superiority as the mursyid rather than the female one. Because of the phenomenon, the paper is written, to explore the issues on male and female role in the Sufism, specifically, for becoming the mursyid. It is expected to be powerful and meaningful cultural analysis which is viewed from tasawufparadigm.
\end{abstract}

Key words: culture, Islam civilization, tasawuf ritual, and female mursyid.

\section{Pendahuluan}

Tasawuf, sebagaimana banyak peminat kajian ini mengungkapkan, sering diartikan sebagai pengembaraan pemikiran dan perasaan yang menurut tabiatnya sulit didefinisikan. Dia muncul dalam kaitan upaya akal manusia untuk memahami hakikat segala sesuatu, dan untuk menikmati pengalam-an ma'rifat pada Allah (Simuh, 1994: 70). Meskipun demikian, semua sufi akan mengalami "pengalaman" yang sama yaitu pengalaman untuk menuju ma'rifat kepada Allah, . Hal ini karena tasawuf (pada dasarnya) merupakan suatu ilmu yang ajarannya mengarahkan kepada penjernihan hati, untuk menghadapi segala permasalahan kehidupan dunia, dengan sikap tidak larut dan tenggelam dalam kehidupan dunia tersebut, 
melainkan berusaha untuk menggapai kesempurnaan diri dengan mendekati Tuhan (Depag RI, 1987: 19).

Tasawuf sebagai ritual khusus yang sangat penting dilakukan oleh para pelaku tarekat melalui dzikir dengan menyebut nama Allah yang bisa dilakukan secara individu atau bersama-sama, dengan bimbingan langsung sang guru yang telah membaiatnya yang biasa disebut mursid (Bruinessn, 1992: 96).

Akan tetapi, yang menjadi persoalan dalam ritual setiap tarekat yang ada adalah, bahwa hampir mayoritas ritual tarekat menyitrakan Tuhan dalam bentuk atau citra laki-laki dan menganut pola kepemimpinan yang pada ujungnya mengesahkan superioritas laki-laki sebagai seorang mursid ketimbang perempuan.

Perempun dalam konteks yang demikian, senantiasa terkesan dimarginalisasikan, atau sengaja dinomorduakan dengan berbagai asumsi patriarkhis yang terbangun. Apakah benar hal itu merupakan bentuk dari kedangkalan pemahaman atas ajaran tarekat yang menafsirkan substansi nilainya sebatas teks-teks dan bukan konteks (Ali, 1978: 371-375).

Tarekat, sebagai jalan kesucian untuk membebaskan segala bentuk ketidakbenaran, tidaklah mengenal pembedaan atas jenis kelamin. Karena itu, kesalahan perspektif terhadap konsep di dalam ajaran tarekat dewasa ini telah sampai pada pembahasan perempuan, yang oleh sebagian kalangan masih dianggap tabu (Nasution, 1983: 56-57).

Dalam proses selanjutnya terjadi budaya ketidakadilan, karena masingmasing saling menguasai, mendominasi, mendeskriditkan, bahkan saling memusnahkan peran perempuan yang hal itu terlihat kemungkinannya pada jarangnya mursyid-mursyid perempuan di tingkatan jajaran elit tarekat sufistik. Karena fenomena yang demikian itulah, tulisan ini hadir di depan pembaca demi menghasilkan potret peradaban budaya tasawuf yang berkemanusiaan.

\section{Tasawuf, Perempuan dan Mursyid}

Tasawuf, sebagaimana dalam Islam dikenal, merupakan suatu tradisi religius yang telah lama berlangsung di tengah komunitas beragama bahkan 
ada yang mengkalim bahwa tasawuf telah berkembang pada zaman Rasulullah SAW (Hamka, 1981: 38-39). Tasawwuf, sebagaimana dipahami, bertujuan untuk membersihkan jiwa dari sifat tercela dan menghiasinya dengan sifat terpuji. Selain itu, ia juga bertujuan untuk mencetak manusia menjadi mahluk yang semakin baik diridhoi Allah. Lebih dari itu, ia juga bertujuan untuk mendapat ketenangan hati dengan cara musyahadah, marifat billah dan selamat di dunia sampai akhirat (Zuhri, 1995: 48).

Asal kata tasawwuf ini, banyak kalangan yang berbeda pendapat. Ada yang bilang berasal dari kata sufah, yang artinya: "nama surat ijazah orang yang naik haji", bisa juga dari kata kerja shafa yang artinya "bersih" dan "suci" Ada juga yang menanggap dari kata suffah, yaitu ruangan dekat masjid Madinah tempat Rasulullah memberi pelajaran kepada sahabatnya atau diambil dari kata suf yang berarti "bulu kambing" yang dibuat oleh kaum sufi dari Syiria (Nasution, 1983: 56-57).

Tasawwuf disebut juga sebagai mistikisme Islam yang tujuannya sendiri adalah untuk menuju kesederhanaan menjauhi dari sikap riya, sehingga akhirnya menjadi kaum sufi yang mempelajari ilmu tasawwuf (Nasution, 1983: 59). Sedangkang bagi Schimmel (1975), tasawwuf adalah wilayah dan jangkauannya terlalu luas dan tak satupun yang dapat mengurainya secara utuh, karena ia adalah ranah yang sarat dengan pengalaman pribadi (Schimmel, 1975: 37).

Berbeda dengan lainnya, Imam Al Ghozali mendefinisikannya sebagai tuntunan yang dapat menyampaikan manusia mengenal Tuhan dengan sebenar-benarnya, atau disebut marifat (Nata, 2001:236-246). Oleh karena itu tujuan ilmu tasawwuf tidak lain membawa manusia, setingkat demi setingkat kepada Tuhannya. Sehingga tujuan akhir hidup di dunia dan di akhirat nanti dapat tercapai. Sementara menurut Nurcholish Madjid bahwa hal demikian sebagai gejala oposisi kesalehan sebagaimana yang ada di pemerintahan Umayya di Damaskus.

Ajaran ilmu yang berdasarkan kesufian ini adalah untuk mendapatkan keridhoan Allah guna mendapatkan jalan atau tarekat kepada Allah. Jalannya yaitu dengan mujahadah, riyadah, membersihkan hati, mengosongkan dari segala yang berkaitan dengan duniawi. Dalam laku tarekat 
di dalamnya, selalu para murid dibimbing oleh guru yang memberi petunjuk atau yang lebih banyak dikenal dan dinamakan syeh atau mursyid.

Kehadiran seorang mursyid sangatlah penting. Contoh kongkritnya adalah bahwa pengikut atau murid yang belum mendapatkan ijazah pertama kali ia memasuki tarekat. Dari mursyid tidak diperkenankan mengajarkan kepada orang lain. Pelanggaran terhadap ketentuan ini dianggap sebagai pengkhianatan kepada baiat (janji suci) yang diucapkannya ketika pertama kali ia memasuki tarekat (Aqib, 1998: 95-101)

Karena itu, mursyid dalam tarekat menempati kedudukan yang sangat tinggi dan signifikan sebab mursyid berkedudukan sebagai perantara (washilah) antara sang murid dengan Tuhannya. Dengan demikian, mursyid lebih ditinggikan dibanding santri atau murid. Problemnya dalam hal ini adalah bahwa perempuan seringkali dimaknai sebagai santri, yang mungkin saja keberadaannya selalu dinomorduakan jauh di bawah level mursyid.

Mursyid sebagai guru dalam melakukan ritual ketarekatan layaknya pemimpin-syarat di identikan sebagai orang yang harus mempunyai kharisma atau kewibawaan. Faktor kewibawaan yang dimiliki seorang mursyid ini merupakan salah satu kekuatan dalam menciptakan pengaruh di dalam masyarakat (tradisional). Tanpa kewibawaan, seorang mursyid tentu akan kesulitan dalam menciptakan pengaruh (Nata, 1996: 279-282).

Dalam melihat kewibawaan mursyid, paling tidak terdapat dua dimensi yang perlu diperhatikan. Pertama, kewibawaan yang diperoleh seseorang secara given, seperti tubuh yang besar, suara yang keras, dan mata yang tajam serta adanya ikatan geneologis dengan mursyid kharismatik sebelumnya. Kedua, dengan proses perekayasaan. Dalam arti, kharisma diperoleh melalui kemampuan dalam penguasaan terhadap pengetahuan keagamaan disertai moralitas dan kepribadian yang saleh atau salehah, dan kesetiaan menyantuni masyarakat.

Akan tetapi, pandangan umum dalam dunia ketarekatan menilai bahwa kaum perempuan tidak akan bisa sampai kepada kharisma yang dimiliki seorang mursyid laki-laki sebagaimana tertulis di atas. Tetapi yang terjadi dalam sejarah dunia sufistik ternyata berbalik. Yaitu bahwa lelaki tidak selalu harus menjadi simbol "idola" sufi. Kenyataan ini terjadi ketika 
penghulu para sufi, Muhammad SAW, terlihat sangat apresiatif terhadap perempuan. Lihat saja, perkawinannya yang berkali-kali pada dasarnya tidaklah bermaksud merendahkan perempuan tetapi mengangkatnya ke posisi yang tinggi sebagai ummul mukminin (Ali, 1978: 371-375).

Pemujaan Fatimah di kalangan Syi'ah merupakan petunjuk pentingnya peran yang bisa dimainkan perempuan dalam kehidupan keagamaan Islam. Bukti lain yang penting bahwa sufi sejati Islam yang pertama adalah seorang perempuan, Rabiah al-Adawiyah. Ia terkenal sebagai sufi yang cerdas melebihi kaum laki-laki (Arberry, 1985: 74-76).

Rabi'ah adalah "perempuan yang menyendiri dalam keterasingan suci, perempuan yang bercadar ketulusan, perempuan yang terbakar oleh cinta dan kerinduan, luluh dalam penyatuan dengan Tuhan, perempuan yang diterima oleh lelaki sebagai Maryam tanpa noda yang kedua". Rabialı -pada umumnya- dianggap sebagai orang yang memperkenalkan gagasan cirita (mahabbah) tanpa pamrih ke dalam ajaran-ajaran zahid awal. Cintanya vada Tuhan tidak bisa ditawar-tawar lagi, mutlak adanya (Hamka, 1981: 43).

Dengan demikian, kehebatan tasawuf perempuan Rabi'ah ini memberikan warna tasawuf sejati. Tidak ada lagi tempat bagi pikiran-pikiran cinta lain. Ia memilih untuk tidak menikah dan selalu menolak setiap lakilaki yang datang meminangnya. Baginya, cintanya pada Tuhan tidak memungkinkan mencintai seorang pun atau apa pun yang ada di dunia ini. Dia pusatkan seluruh kehendak jiwanya pada kekasih yang dicintainya (Hamka, 1981:39).

Meskipun demikian, sejarah menunjukkan bahwa Rabiah bukanlah satu-satunya sufi wanita yang hidup pada masa awal perkembangan tasawuf. Margareth Smith (1997) telah mengumpulkan bahan-bahan tentang kehidupan beberapa rekan sezaman Rabi'ah, wanita-wanita sufi yang hidup pada akhir abad ke-8 di Basta, Irak, dan Syria. Di antara mereka, terdapat Maryam dari Basra dan Riana, "yang berkobar-kobar semangatnya" (alwalihah).

Data sejarah yang demikian, seharusnya menjadi inspirasi para kaum elit yang berada di institusi kesufian untuk tidak selalu memprioritaskan kaum laki-laki menjadi mursyid, namun sebaliknya juga menjadikan kaum perempuan berpeluang untuk menjadi mursyid. Penunjukkan perempuan 
sebagai mursyid ini adalah sebagai bentuk memahami substansi dan nilainilai keagungan sekaligus penghormatan yang dimiliki kaum perempuan.

Di sinilah, inti kebenaran risalah Islam yang dibawa Rasulullah saw, yang meletakkan dasar pertama atas penghormatan terhadap kaum perempuan (Ali, 1978: 371-375). Bukan seperti ditafsir sebagian pemikir yang memandang "kesataran" kaum perempuan dan laki-laki hanya sebatas fungsi dan peran di ranah publik saja. Sebab Islam lebih jauh telah menempatkan kaum perempuan sebagai "tuan" yang harus dihormati dan dirindukan kaum laki-laki. Dalam paradigma agama, bahwa laki-laki dengan perempuan adalah kesepasangan yang saling membutuhkan, mengisi, dan bukan saling berbenturan apalagi menghinakan.

Kalau kita menelusuri peran perempuan pada masa awal Islam, misalkan, maka banyak sekali temuan betapa kaum perempuan (muslimah) telah memainkan peran yang sangat penting, terutama keikutsertaan mereka dalam mendukung dan membantu perjuangan Rasulullah SAW (Engineer, 1994: 43-45). Perempuan-perempuan yang mendukung risalah spiritualitas dan dakwah Islam adalah seperti yang diperankan Khadijah binti Khuwailid, istri Nabi saw, dan Sumayyah Ummu binti Yasir yang menjadi martir perjuangan Islam dan ia gugur syuhada.

Kaum perempuan ketika itu terlibat secara lebih luas, seperti pendidik, pengajar yang secara aktif melakukan upaya-upaya transformasi nilai-nilai ke-Islaman di masyarakat terutama tentang Quran dan hadis sebagaimana diperankan Aisyah. Demikian ajaran Islam telah menempatkan kaum perempuan memiliki hak, peran, dan kewajiban yang sama dengan laki-laki terutama terkait dengan urusan publik. Bahkan Rasul saw, pada ujung hayat beliau memberi ultimatum agar kaum perempuan dijaga dan dihormati; lewat ucapan "as-shalah, ummati, an-nisa" (salat, umat, dan kaum perempuan) (Ali, 1978: 371-375).

Selanjutnya pada era khulafa al-rasyidin, posisi dan peran perempuan dapat menikmati kebebasan yang cukup dengan berinteraksi di ruang publik seperti halnya mendengar khutbah dan ceramah yang disampaikan sahabat laki-laki. Tokoh perempuan seperti Ummu Abdillah bin Zubair yang terkenal dengan pengetahuan agamanya yang konprehensif, juga ditemukan di sana. 
Amrah binti Abd Rahman yang terpandang karena kedalaman ilmu fiqih dan kezahidannya serta tergolong ulama besar yang dapat memberi fatwa di Madinah setelah sahabat-sahabat Nabi, juga ditemukan di sana. Kemudian Hafsah binti Sirin yang terkenal sebagai ahli hadis dari Basrah yang dapat dijumpai dalam shahih Bukhari dan shahih Muslim, juga menunjukkan bahwa kaum perempuan tidak bisa diangap remeh.

Sejarawan Ibnu Asakir (w.571/1125 M) mengakui pernah belajar kepada lebih 80 ulama perempuan. Ulama hadis dan fiqih terkenal Ibnu Hajar Al-Asqalani mencatat 53 perempuan yang menjadi sumber dalam peri-wayatan hadis. Jadi keberadaan perempuan sebagai ulama (spiritualis hukum), tidak bisa dipungkiri dalam realitas sejarah Islam. Islam secara normatif memberikan peluang dan kesempatan yang sama kepada lakilaki dan perempuan untuk menuntut ilmu sebanyak-banyaknya dan berperan sesuai dengan kemampuan dan kapasitasnya untuk mengabdikan ilmunya di tengah masyarakat.

Dewasa ini, seperti halnya sikap Ayatullah Khomeini terhadap kaum perempuan, sangat menghormati. Terhadap isterinya, Khomeini tidak pernah marah, kalaupun merasa tidak senang dia menggunakan sindiran halus. Begitu pun kepada putrinya, Saidah Zahra yang profesor filsafat di Universitas Teheran, tidak pernah menanyakan setiap dia akan keluar rumah. Karena Khomeini percaya kepada putrinya dan membiarkan putrinya mengejar karier keilmuan. Dalam wasiatnya kepada putranya, Ahmad, Khomeini mengatakan "seseorang tidak bisa menghitung nilai perbuatan satu malam yang dijalani seorang ibu untuk mengurusi anaknya. Nilainya jauh lebih besar dari bertahun-tahun hidup yang dijalani seorang suami yang setia".

Khomeini, sebagai pemimpin agama di Iran misalkan, tidak raguragu melakukan pekerjaan rumah tangga, seperti mencuci piring. Ini sekaligus mematahkan mitos bahwa tempat perempuan adalah di rumah dan mengerjakan tugas-tugas rumah tangga, sementara laki-laki bekerja di luar rumah. Karena tidak ada ayat al-Quran yang membatasi perempuan bekerja di luar rumah. 
Banyak contoh pada zaman Nabi perempuan bekerja mencari nafkah. Istri yang sangat disayangi Nabi, Siti Khadijah, berprofesi sebagai pedagang. Putri Nabi saw, Siti Fatimah, ikut bekerja mencari nafkah karena suaminya, Ali, yang memilih terjun ke politik (Muthahari, 1997: 45-46).

Bila memahami perspektif spiritualitas Islam sejak kelahirannya, maka ketika terjadi benturan dengan tuntutan sosial atas peran perempuan, berbagai diskursus yang muncul dan cenderung menyudutkan kaum perempuan haruslah ditelaah ulang, harus diluruskan agar persepsi bahwa kaum lakilaki lebih unggul dari pada kằum perempuan, tidak makin membias dan menjadi benturan-benturan nilai. Termasuk di dalam wilayah ketarekatan, kesufian dan kespiritualan yang lebih luas kompleksnya.

Jika banyak kalangan yang berbicara tentang ketimpangan sosial berdasarkan jenis kelamin, sungguh hanya pemahaman dangkal mereka atas subtansi agama. Sebab ajaran spiritualitas Islam tidak sejalan dengan paham patriarki yang tidak memberikan peluang bagi perempuan untuk berkarya lebih besar. Tentunya dengan demikian, disuportnya kaum perempuan untuk tidak menghindari adanya penunjukkan menjadi mursyid, sangat penting diperhatikan. Hal itu karena perempuan dan laki-laki mempunyai peluang yang sama menjadi pemimpin dalam hal apapun termasuk di dalam wilayah kepemimpinan tarekat-spiritual (Baca; peluang Mursyid).

\section{Tasawuf Masa Kini; Upaya Menuju Budaya Peradaban Tasawuf yang Berkeadilan bagi Kaum Perempuan}

Islam, pada dasarnya, berusaha mengubah nasib perempuan menjadi kelompok paling beruntung. Islam ingin memanusiakan perempuan seperti layaknya laki-laki. Semua janji tentang pahala dan dosa tidak dibedakan bagi keduanya. Laki-laki dan perempuan sama-sama berpotensi menjadi hamba idola yang muttaqin, serta sama-sama bertanggungjawab sebagai khalifah di bumi, termasuk menjadi guru tarekat (mursyid).

Hal itu karena Islam mengakui adanya kesetaraan. Ini jelas dan sangat terang sekali dicontohkan Rasulullah Saw dalam kehidupannya termasuk juga al-Qur'an menegaskan secara konkrit mengenainya. Siapapun hambanya, baik laki-laki maupun perempuan, jika memenuhi syarat, layak dari 
kesemuanya menjadi pemimpin di segala bidang, termasuk dalam sebuah ordo tarekat.

Begitu pula tasawwuf, sebagai salah satu media olah spiritual yang nantinya akan menghasilkan sesuatu yang bersifat spirit dan mendorong terbitnya nilai-nilai etika dan melahirkan daya sensitifitas positif dalam peranannya sebagai hamba dan sekaligus khalifah, meyakini bahwa sifat keadilan sangatlah penting untuk diterapkan termasuk adil jender dalam relung jiwa ketarekatan. Artinya, ketika ritual ketarekatan masih saja membeda-bedakan tingkatan dan kemulyaan hanya karena status kelamin seorang hamba misalkan, tentua ajaran hakikat tasawuf tidak akan bakal bisa ditemukan. Bahkan tasawuf menjadi tempat perusak ajaran Islam yang sesungguhnya karena memarjinalkan kaum perempuan.

Karena itu, pengaruh utama jender dalam disiplin spirit ketarekatan layak untuk dipahami bersama dengan bentuk memberikan peluang bagi kaum perempuan untuk menjadi mursyid jika sudah memenuhi syarat. Apa gunanya mendekatkan diri kepada Tuhan yang Maha Kasih Yang Maha Adil, jika ternyata hati dan perilaku tarekat kita masih saja membeda-bedakan status kelamin. Padahal status dihadapan Tuhan -pada dasarnya- adalah sama, kecuali ketaqwaan.

Baik perempuan maupun laki-laki, dihadapan Allah adalah sama, karena yang dilihat Allah bukanlah jenis kelamin setiap hamba melainkan derajat taqwa masing-masing individu. Sebagaimana hal ini bisa dilihat dalam nama-nama perempuan shalihah seperti: Rabi'ah al-Adawiyah (dari Basrah), Maryam al-Basriyyah, Bahriyya al-Mausuliyyah, Rihana al-Waliha, Sya wana, dan lain sebagainya (Arberry, 1985: 77-78).

Mencerminkan tasawuf yang bersih suci dan arif, sudah sepatutnya manajemen ritual tasawuf dialihkan dari yang semula tasawuf patriarkhis menuju tasawuf humanis untuk melahirkan potret tasawuf pembebasan. Yang mulanya "tasawuf melarang perempuan menjadi mursyid" dirubah menjadi "tasawuf yang memberikan peluang sama" kepada kaum laki-laki dan perempuan untuk menjadi mursyid sebagaimana Rabi'ah. Hal yang demikian penting diapresiasi mengingat sejak zaman nabi hingga pasca nabi, perempuan tetap memainkan peranan penting (Nasution, 1983: 56-57). 
Di antara kaum perempuan sufi yang cukup berperan dalam wilayah spiritual selain Rabi'ah al-Adawiyah adalah; Rabi'ah binti Ismail dari Syria. Ia sering dikacaukan dengan nama sufi besar Rabi'ah al-'Adawiyah, akan tetapi karena ia menikah, menetap dan meninggal di Syiria 50 tahun sebelum Rabi'ah al-'Adawiyah, maka cukup jelas perbedaan keduanya.

Rabi'ah binti Ismail yang dikenal sangat asketis (zuhud) ini, mendapatkan penghormatan yang tinggi di antara para Sufi semasanya dan banyak orang yang berkonsultasi dan meminta penjelasan tentang masalah-masalah tasawuf kepadanya. Di antara keajaibannya, Rabi'ah melihat informasi akan meninggalnya Harun ar-Rasyid di sebuah tempayang (genthong isi air) yang ada di hadapannya dan beberapa hari kemuadian Harun ar-Rasyid ternyata benar-benar meninggal (Smith, 1997: 163).

Perempuan sufi terkenal lainnya adalah, Mu'adzah al-'Adawiyah. Ia seorang sahabat Rabi'ah al-'Adawiyah. Mu'adzah, sebagaimana ia dipanggil, adalah salah seorang anggota aliran Hasan al-Bashri yang menitikberatkan pada kezuhudan dari pada mistikisme. Pandangan hidupnya sama dengan Hasan al-Bashri, yaitu bahwa hidup selalu di bawah bayangan takut akan kemurkaan yang akan datang. Ibadah yang dilakukannya sangat sulit untuk ditiru karena selama 40 tahun ia tidak pernah mendongakkan kepalanya ke atas langit, tidak pernah makan sesuatupun di siang hari dan tidak pernah tidur di malam hari serta biasa melakukan salat sebanyak 600 rakaat sehari semalam. Itulah karakteristik Rabi'ah dalam upaya mendapatkan kebahagiaan disisi Allah Swt (Smith, 1997: 159).

Seorang sufi perempuan agung lainnya adalah Nafisah, buyut Hasan bin Ali yang lahir di Mekah tahun $145 \mathrm{H}$ dan tumbuh dewasa di Madinah. Ia menikah dengan Ishaq, putra Imam Ja'far ash-Shadiq dan dikaruniai dua orang anak, yaitu al-Qasim dan Ummu Kultsum. Sebagaimana para sufi lainnya ia menghabiskan siang harinya dengan berpuasa dan menghabiskan malamnya dengan ibadah salat. Ia sangat terkenal dengan pengetahuannya tentang kitab al-Quran beserta tafsirnya (Smith, 1997: 160).

Mengenai Nafisah ini, mujtahid besar sekaliber Imam Syafi'i sering mengunjunginya dan mengadakan diskusi. Penghormatan imam Syafi'i dapat dilihat dari seringnya beliau mengadakan salat-salat khusus dengan Nafisah di bulan Ramadhan. Nafisah dikenal di seluruh Mesir dan kemana 
saja ia pergi reputasinya selalu mengikutinya dan ia selalu menerima penghormatan dari masyarakat baik individu ataupun kelompok. Akhirnya ia wafat di Mesir pada bulan Ramadhan tahun $208 \mathrm{H}$.

Perempuan sufi lainnya yang termasuk dalam kelompok Syeikha (mursyidah) adalah Zaynab, putri Abu al-Qasyim 'Abdur Rahman asy-Syari. Ia lahir di Naysabur pada tahun 1130 dan meninggal pada tahun $1219 \mathrm{M}$. la termasuk sebagai murid terbaik di masanya sehingga mendapatkan ijazah untuk mengajarkan tentang ilmu Hadits. Dan ia mendapat pengakuan dari murid-muridnya tentang kesalehannya, seperti Ibnu Khallikan, Ibnu Batutah dan Ummu Muhammad Aisyah, Zainab binti Kamaluddin.

Dengan demikian, angan-angan tasawuf yang berbasis mursyid perempuan pada dasarnya tidaklah menjadi bermasalah bahkan sangat positif dan penting untuk segera dikampanyekan demi menegakan keadilan berperan seimbang sesama mahluk Tuhan. Karena itulah, tak ayal jika seorang ahli mistik Islam sekaligus feminis (berasal dari Jerman) bernama Annemarie Schimmel menyontohkan bahwa Rabiah telah menandai awal gerakan mistik yang sesungguhnya dalam Islam. Dia telah mengubah asketisme yang sebelumnya suram menjadi mistisisme cinta kasih murni yang indah (Schiemel, 1975: 46).

Akhirnya, dengan tidak menghalang-halangi kaum perempuan untuk menjadi seorang mursyid, paling tidak akan menjadikan pertanda akan bangkitnya ajaran tasawuf pembebasan yang humanis dengan bentuk dihormatinya seluruh kaum perempuan di dunia ini. Tentunya selain itu, disiplin ilmu tasawuf dengan ritual tarekatnya yang dipimpin mursyid perempuan diharapkan- dapat memberikan konsep kesetaraan yang tepat dan tidak lagi (terkesan) mengkerdilkan kaum perempuan sebagaimana terlihat pada upacara ritual yang melulu harus dipimpin seorang mursyid laki-laki.

\section{Simpulan}

Dari sekian pembacaan di atas, ada beberapa kesimpulan yang penting untuk diperhatikan, di antaranya adalah sebagai berikut:

Pertama, peradaban budaya Islam khususnya di bidang ajaran spiritualitas Islam, pada dasarnya, tidak sejalan dengan paham patriarki 
yang tidak memberikan peluang bagi perempuan untuk berkarya lebih besar. Dalam budaya Islam, laki-laki dengan perempuan adalah kesepasangan yang saling membutuhkan, mengisi, dan bukan saling berbenturan apalagi menghinakan. Bahkan ajaran budaya dasar spiritual Islam hakikatnya adalah memberikan kaum perempuan untuk memili ki hak, peran, dan kewajiban yang sama dengan laki-laki termasuk dalam hal menempati posisi sebagai pemimpin mursyid. Karena itu, institusi kesufian tidak penting untuk selalu memprioritaskan kaum laki-laki menjadi mursyid, namun sebaliknya juga menjadikan kaum perempuan untuk diberi peluang menjadi mursyid.

Kedua, peradaban budaya yang diinginkan Islam adalah menyatakan bahwa laki-laki dan perempuan sama-sama berpotensi menjadi hamba idola yang muttaqin, serta sama-sama bertanggungjawab sebagai khalifah di bumi, termasuk menjadi guru tarekat (mursyid). Itulah mengapa, penunjukkan perempuan sebagai mursyid pada dasarnya tidak akan mengurangi atau merusak jati diri sifat ketarekatan kelompok sufi tertentu, sebaliknya hal itu merupakan bentuk mengagungkan sekaligus penghormatan kepada Tuhan sebagai pencipta. Karena itulah, tasawuf berbasis mursyid perempuan sudah selayaknya dipublikkan demi mengembalikan sejarah peradaban budaya ajaran-ajaran dasar Islam yang mengakui adanya kesamaan dan kesejajaran antara kaum laki-laki dan perempuan.

\section{Daftar Pustaka}

Ali, Amer. 1978. Api Islam. Sejarah Evolusi dan Cita-Cita Islam dengan Riwayat Hidup Muhammad. Jakarta: Bulan Bintang.

Aqib, Harisuddin. 1998. Al-Hikmah: Memahami Teosofi Tarekat, Qadiriyah wa Naqsyabandiyah. Surabaya: Bina Ilmu.

Arberry, A.J. 1985. Sufism; An Account of The Mystics of Islam. Terjemahan oleh Bambang Herawan. Pasang Surut Aliran Tasawuf. Bandung: Mizan.

Bruinessen, Van Martin. 1992. Tarekat Naqsyabandiyah di Indonesi. Bandung: Mizan.

Departemen Agama RI, Ensiklopedi Islam, edisi 1987, "Tasawuf". 
Engineer, Asghar Ali. 1994. Hak-Hak Perempuan dalam Islam. Terjemahan oleh Tim LSPPA. Yogyakarta: LSPPA.

Ghazali, Al-Imam. Ihya' Ulumuddin. Beirut: Dar al-Fikr, III, t.t.

Hamka. 1981. Tasawuf: Perkembangan 8 Pemumiannya. Jakarta: Yayasan Nurul Islami.

Hassan, Riffat. 1995. Setara di hadapan Allah; Relasi Laki-laki dan Perempuan dalam Tradisi Islam Pasca Patriarkhi. Yogyakarta: Yayasan Prakarsa.

Mernisi, Fatima, dan Riffat Hassan. 1995. Setara di hadapan Allah; Relasi laki-laki dan Perempuan dalam tradisi Islam Pasca Patriarkhi. Yogyakarta: Yayasan Prakarsa.

Musthafa, Zuhri. 1995. Kunci Memahami Ilmu Tasauuf (Cetakan ke-1). Surabaya: Bina Ilmu.

Muthahari, Murtadha. 1997. Hak-Hak Wanita dalam Islam (Cetakan ke-4). Terjemahan oleh M. Hashem. Bandung: Lentera Basritama.

Nasr, Sayyid Husein. 1985. Tasawuf Dulu dan Sekarang. Terjemahan oleh Abdul Hadi WM, Jakarta: Pustaka Firdaus.

Nasution, Harun. 1983. Falsafat dan Mistisisme dalam Islam (Cetakan ke-3). Jakarta: Bulan Bintang.

Nata, Abuddin. 1996. Akhlaq Tasawwuf (Cetakan ke-1). Jakarta: PT Raja Grafindo Persada.

Nata, Abuddin. 2001. Metodologi Studi Islam. Jakarta: PT Raja Grafindo Persada.

Schiemel, Annemarie. 1975. Mistik Islam. Terjemahan oleh Sapardi Djoko Darmono. Jakarta: Pustaka Firdaus.

Simuh. 1994. Pemikiran dalam Bidang Tasawwuf. Jumal Al-Jami'ah. IAIN Sunan Kalijaga Yogyakarta, No. 57.

Smith, Margaret. 1997. Rabi'ah; Pergulatan Spiritual Perempuan. Terjemahan oleh Jamilah Baraja. Surabaya; Risalah Gusti. 